\title{
Are physical activity studies in Hispanics meeting reporting guidelines for continuous monitoring technology? A systematic review
}

Charles S. Layne', Nathan H. Parker', Erica G. Soltero' ${ }^{1}$, José Rosales Chavez², Daniel P. O'Connor ${ }^{1}$, Martina R. Gallagher ${ }^{3}$ and Rebecca E. Lee ${ }^{*}$

\begin{abstract}
Background: Continuous monitoring technologies such as accelerometers and pedometers are the gold standard for physical activity (PA) measurement. However, inconsistencies in use, analysis, and reporting limit the understanding of dose-response relationships involving PA and the ability to make comparisons across studies and population subgroups. These issues are particularly detrimental to the study of PA across different ethnicities with different PA habits. This systematic review examined the inclusion of published guidelines involving data collection, processing, and reporting among articles using accelerometers or pedometers in Hispanic or Latino populations.

Methods: English (PubMed; EbscoHost) and Spanish (SCIELO; Biblioteca Virtual en Salud) articles published between 2000 and 2013 using accelerometers or pedometers to measure PA among Hispanics or Latinos were identified through systematic literature searches. Of the 253 abstracts which were initially reviewed, 57 met eligibility criteria (44 accelerometer, 13 pedometer). Articles were coded and reviewed to evaluate compliance with recommended guidelines $(N=20)$, and the percentage of accelerometer and pedometer articles following each guideline were computed and reported.

Results: On average, $57.1 \%$ of accelerometer and $62.2 \%$ of pedometer articles reported each recommended guideline for data collection. Device manufacturer and model were reported most frequently, and provision of instructions for device wear in Spanish was reported least frequently. On average, $29.6 \%$ of accelerometer articles reported each guideline for data processing. Definitions of an acceptable day for inclusion in analyses were reported most frequently, and definitions of an acceptable hour for inclusion in analyses were reported least frequently. On average, $18.8 \%$ of accelerometer and $85.7 \%$ of pedometer articles included each guideline for data reporting. Accelerometer articles most frequently included average number of valid days and least frequently included percentage of wear time.

Discussion: Inclusion of standard collection and reporting procedures in studies using continuous monitoring devices in Hispanic or Latino population is generally low.

Conclusions: Lack of reporting consistency in continuous monitoring studies limits researchers' ability to compare studies or draw meaningful conclusions concerning amounts, quality, and benefits of PA among Hispanic or Latino populations. Reporting data collection, computation, and decision-making standards should be required. Improved interpretability would allow practitioners and researchers to apply scientific findings to promote PA.
\end{abstract}

Keywords: Accelerometry, Pedometry, Evidence-based practice, Latinos, Measurement

\footnotetext{
* Correspondence: releephd@yahoo.com

${ }^{4}$ Center for Health Promotion and Disease Prevention, College of Nursing and Health Innovation, Arizona State University, 500 N. 3rd Street, Phoenix, AZ 85004, USA

Full list of author information is available at the end of the article
}

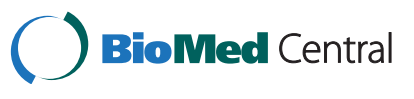

(c) 2015 Layne et al. Open Access This article is distributed under the terms of the Creative Commons Attribution 4.0 International License (http://creativecommons.org/licenses/by/4.0/, which permits unrestricted use, distribution, and reproduction in any medium, provided you give appropriate credit to the original author(s) and the source, provide a link to the Creative Commons license, and indicate if changes were made. The Creative Commons Public Domain Dedication waiver (http://creativecommons.org/publicdomain/zero/1.0/) applies to the data made available in this article, unless otherwise stated. 


\section{Background}

The study of PA has allowed researchers to make significant gains in understanding relationships between PA and related health benefits across a variety of environments and populations [1]. Continuous monitoring technologies such as accelerometers and pedometers have become the gold standard for measurement, and because they are less subjective and uninfluenced by recall, are generally preferred over self-report measures such as questionnaires and surveys [2-7]. Accelerometers measure body movements using piezoelectric sensors and more recently piezoresistive and capacitive technology to monitor acceleration in one to three orthogonal planes $[1,8,9]$. Pedometers are motion sensors worn on the waistband or belt, that use a spring-suspended lever arm that moves concordantly with hip acceleration and deceleration to measure walking distance [10]. Accelerometers are typically preferred over pedometers due to their ability to estimate general PA level and energy expenditure rather than only walking pace and distance [6].

Although continuous monitoring technologies offer more reliable and valid estimates of PA levels, challenges associated with these objective methods such as cost and lack of expertise initially limited their use [6]. Today, technological advances, widespread application, and cost reductions have made accelerometers and pedometers more accessible to researchers interested in assessing PA [6]. As pedometer and accelerometer use has increased, researchers have recognized the need to establish a set of standards and recommendations for procedures involving data collection, processing and reporting of the complex data that are obtained from these continuous monitoring devices. In 2004, the landmark conference 'Objective Monitoring of PA: Closing the Gaps in the Science of Accelerometry' addressed inconsistencies in the use, analysis, and interpretation of data obtained from continuous monitoring devices and presented recommendations for achieving standardized use of accelerometers and pedometers [6]. Recommendations included guidelines for the type of device used for specific outcome measures, monitor wear, calibration and sensitivity monitoring, data collection, data filtering and the handling of missing or incomplete data [6]. Many of the concerns expressed by Ward et al. persist today and continue to be debated, indicating that a consensus has not been achieved by PA researchers [11-15]. Lack of consensus and inconsistent reporting limits our ability to make comparisons across studies and understand the dose-response relationship between PA and health outcomes [16]. Non-uniform reporting hampers development of accurate research, policy, and national guidelines such as the recommendations for PA $[11,12]$.

Although a vexing problem across the realm of PA research, inconsistent standards of data collection, processing and reporting can have a larger impact on the study of PA in specific population subgroups such as Hispanics and Latinos [6]. Significant disparities in PA exist among Hispanics in the U.S. and Latin America. National reports in the US have shown that Hispanics consistently report lower levels (14.4\%) of PA compared to nonHispanic whites (22.8\%) [17]. International reports have shown that the rate of physical inactivity among Hispanics in Latin America is $43.2 \%$, reaching as high as $68 \%$ in some countries such as Argentina and Columbia [18]. These low rates of PA have led to the increased prevalence of obesity and development of chronic diseases such as cardiovascular diseases and diabetes in Hispanic populations, especially in low- to middle-income countries in Latin America. The World Health Organization estimates that $80 \%$ of deaths in Latin American countries are attributed to non-communicable diseases [19]. These diseases also carry significant economic consequences, often limiting the social and economic development of the country [20]. Despite these statistics, without standardized practices and reporting guidelines for continuous monitoring devices, researchers are prevented from accurately quantifying PA patterns and related health outcomes in this population [21]. Without standard practices and reporting, researchers are unable to effectively generalize the level of PA and are prevented from making comparisons across studies between Hispanics and other ethnic populations or comparisons within groups of Hispanics [21]. As Hispanics have been identified as a vulnerable population, it is important that standardized practices are implemented and reported for the effective use of continuous monitoring devices in this population.

A systematic review of literature concerning the assessment of PA in Hispanics using continuous monitoring technologies is both timely and warranted. The assessment of PA patterns and their relationships to obesityrelated conditions and behaviors in vulnerable populations such as Hispanics has taken on increased importance as preventive models of health care have emerged. This study aimed to compare the reporting of objectively measured PA variables in studies using continuous monitoring devices in Hispanic populations to published, state of the science guidelines about data acquisition, processing, and reporting.

\section{Methods}

\section{Selection of studies}

We systematically identified articles in English or Spanish published between 2000 and 2013 (last search date June 1, 2014) that measured PA among Hispanic or Latino populations of any age living in the United States, Mexico, and South American countries, excluding Brazil as it is economically and culturally different from the other countries that comprise Latin America [21]. We searched PubMed 
and Ebscohost for English language articles, and we searched SCIELO and Biblioteca Virtual en Salud for Spanish Language articles. Our searches in these databases included the following terms: "Hispanic and accelerometer", "Mexican and accelerometer", "Latino and accelerometer", "Acelometro", "Hispanic and pedometer", "Mexican and pedometer", "Latino and pedometer" and "pedometro" [22]. Search terms identified studies including Mexican-Americans, as this is the largest and most prevalent group of Hispanics in the U.S. [23]. This search and an examination of titles produced a total of 228 articles (225 in English, 3 in Spanish), which underwent initial abstract review for use of continuous monitoring technologies (accelerometers and/or pedometers). Articles were further screened for the following criteria: 1) PA as a primary outcome, 2) sample included at least $33 \%$ Hispanic or Latino, and, for articles including multiethnic samples, 3) stratification of continuous monitoring results for ethnicity. For articles on which two reviewers disagreed regarding inclusion, the reviewers discussed rationale for inclusion or exclusion and referred one another to evidence in the text until consensus was reached. Sixtyfive articles (63 in English, 2 in Spanish) met all inclusion criteria and underwent final review. If multiple articles reported results from the same study or dataset, the article including the most complete accelerometry data was included in analyses. Eight articles were eliminated accordingly, leaving 57 articles (55 in English, 2 in Spanish) for analyses. Figure 1 presents the number of articles identified, the number of articles included and excluded, and the rationale for inclusion or exclusion for each step of the systematic search.

\section{Development and application of reporting guidelines}

The purpose of this systematic review was to compare the reporting of continuous monitoring variables in the PA literature involving Hispanic samples to the published guidelines regarding data collection, processing and reporting of continuous PA monitoring. Eighteen reporting guidelines were extracted from the 2005 article by Ward et al. outlining areas for researchers to improve the validity of data collected using accelerometers in studies of PA [6]. Each of the guidelines included in this review was identified by Ward et al. as a "best practice" in continuous monitoring data collection that, with standardized reporting, facilitates data analysis and cross-study comparisons. Two reporting guidelines were added for applicability to studies involving Hispanic or Latino populations ("Provision of instructions

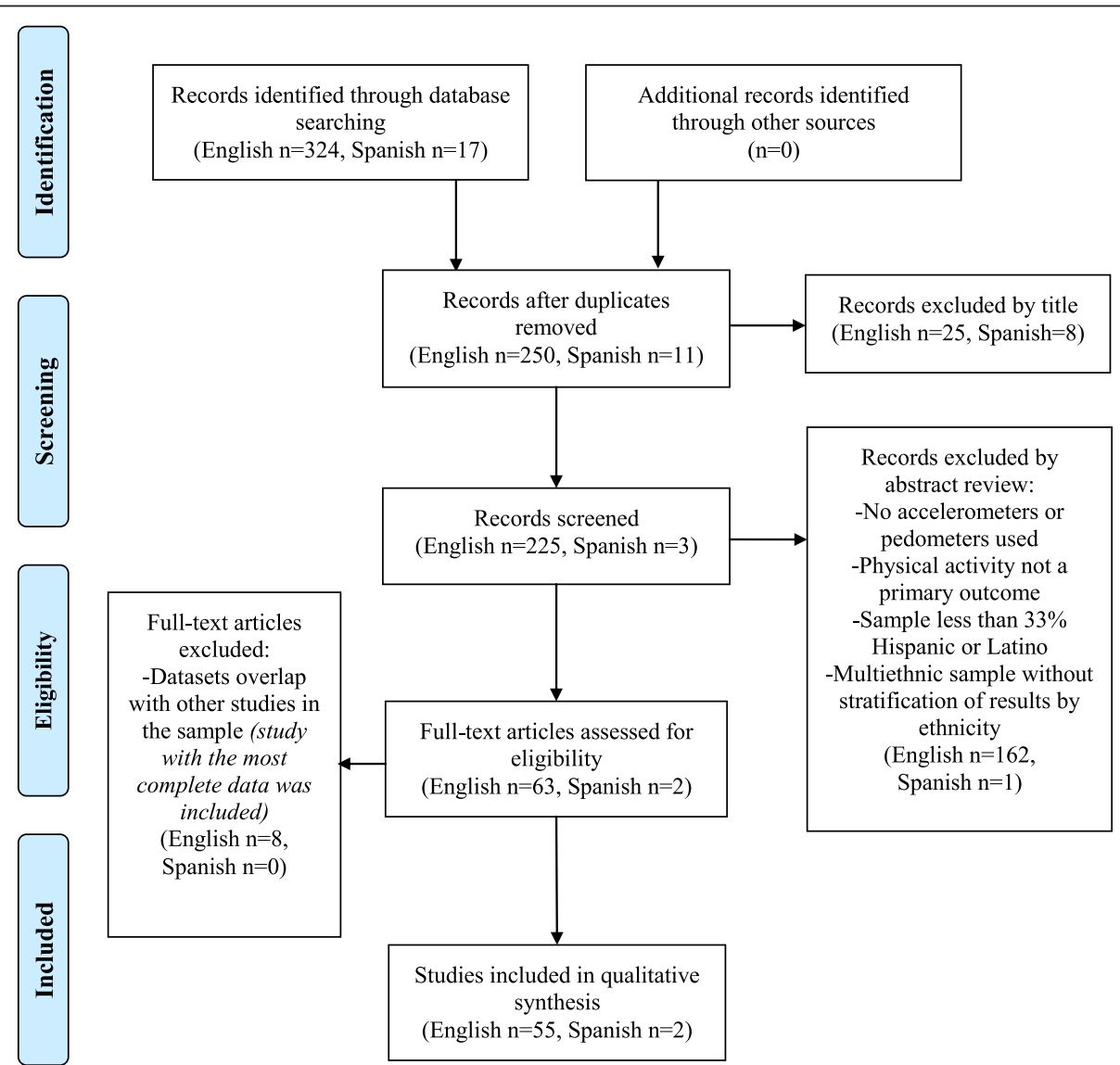

Fig. 1 Selection of accelerometer and pedometer studies for systematic review (PRISMA 2009 Flow Diagram) 
for device wear in Spanish") and studies using pedometers ("Total step counts"). All reporting guidelines are presented in Fig. 2.

Among the 20 reporting guidelines applied to the articles reviewed, 7 were parameters governing data collection, 4 were parameters governing data definitions and processing, and 9 were reporting standards for summary variables (Fig. 2). All articles were coded with "yes" or "no" depending on whether they reported each guideline. The Ward, et al. article establishes recommended levels at which three of the reporting guidelines should be set in studies involving continuous PA monitoring: number of days of device wear required for inclusion in analyses, epoch length, and length of continuous PA sessions [6]. For these guidelines, articles were coded for both inclusion (yes/no) and the actual level applied to data collection or data inclusion (e.g. collecting accelerometry data in

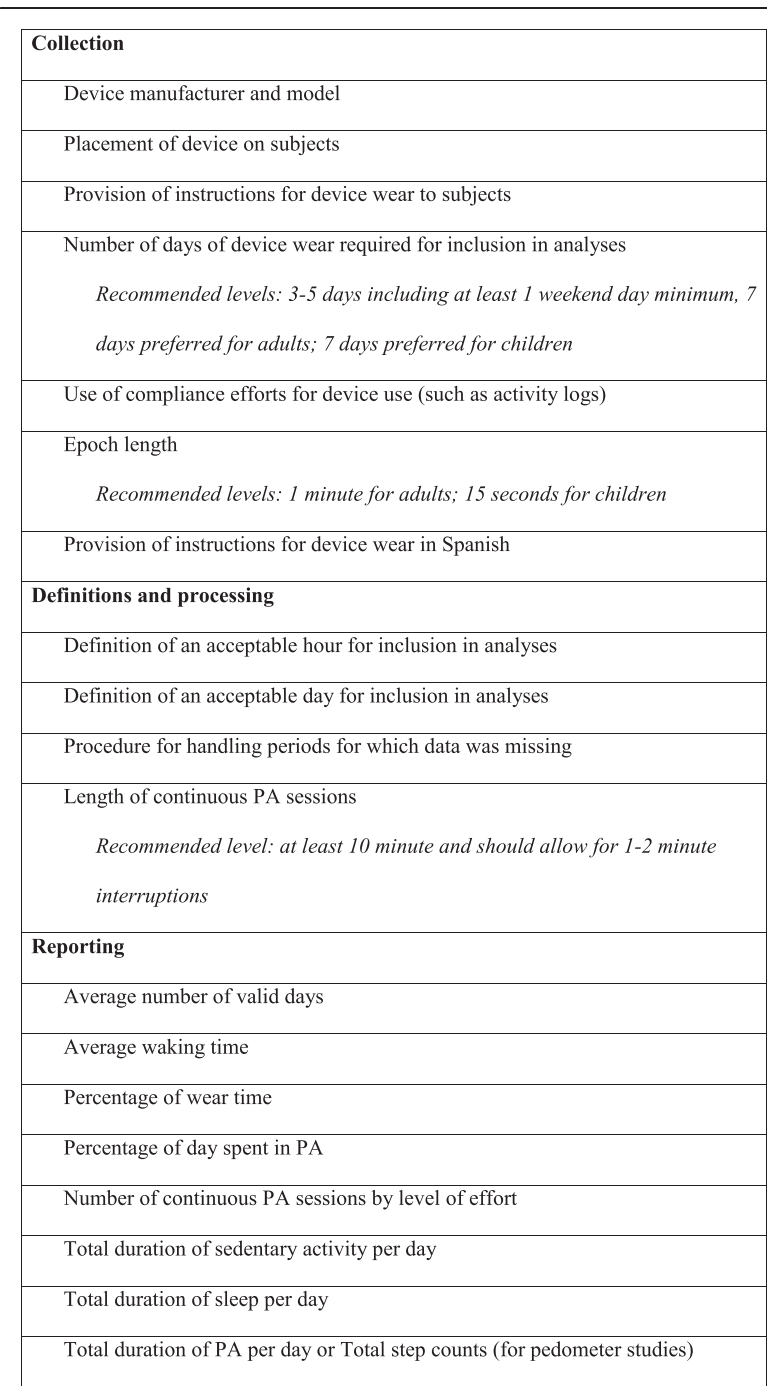

Fig. 2 Gold standards in accelerometry and pedometry data reporting epoch lengths of $1 \mathrm{~min}$ and processing data into continuous PA sessions of $10 \mathrm{~min}$ or longer) (Fig. 2).

\section{Collection of descriptive and contextual information}

In addition to the 20 reporting guidelines for continuous monitoring technologies, coders recorded identifying, descriptive, and contextual information from each article. The six identifying characteristics collected included article authors, article title, journal, year, volume/issue, and page numbers. The 10 general descriptive and contextual characteristics collected included, when applicable and described in articles, the name of trial or study, type of study, a description of the study's intervention, groups by which data were reported, subject ethnicities, inclusion criteria, study location, study environment (urban/suburban by default, rural when stated explicitly by authors), intervention setting, and assessment setting. The final five descriptive and contextual characteristics applied only to the Hispanic or Latino subjects for whom continuous monitoring variables were reported: number of participants, gender, number of females, number of overweight or obese, and age.

\section{Coding protocol}

Ten trained coders participated in article coding. Training was completed in two sessions. In the first training session, coders were given a codebook that listed all reporting guidelines and contextual variables. The codebook provided operational definitions for each code as well as examples of plausible answers that were likely to be reported in the literature. Coders were trained on how to complete each coding category on the coding sheet using definitions from the codebook. Coders were instructed to complete each category with "yes" to indicate the inclusion of a reporting guideline or "no" to indicate the absence of a reporting guideline. For the three guidelines involving set recommended levels (Fig. 2), coders were also instructed to find and record applicable data for these categories. For contextual variables, coders were only instructed to find and record applicable data. Following the first training, coders were divided into pairs and asked to independently code three randomly selected articles for the inclusion of reporting guidelines. In the second training session, coding pairs met to review and compare their coding sheets for the initial three articles. Discrepancies were resolved by referring to the codebook and were discussed as a group to ensure understanding among all coding pairs. Following this training, each member of coding pairs independently coded a list of randomly assigned articles for the presence or absence of the reporting guidelines listed in Fig. 2 and for applicable data regarding the three reporting guidelines with recommended levels. Spanish language articles were assigned to pairs in which both coders could fluently speak and read Spanish. After coding was 
completed, coding pairs met to review and compare coding sheets for all coded articles. Each pair recorded the number of disagreements and agreements for each coding sheet. These values were used to analyze interrater reliability $(n=28)$. Inter-rater reliability was high (Kappa $=0.804)$. Coders then discussed disagreements and resolved them by consensus, referring one another to data in research articles for resolution. Once a consensus was reached, one master coding sheet for each article was submitted for analysis.

\section{Results}

\section{Characteristics of studies}

Contextual information for each of the articles reviewed is listed in Table 1. Of the 57 articles included and coded, 44 utilized accelerometers and 13 utilized pedometers. Approximately $75 \%$ of studies were cross-sectional, and among the 14 longitudinal studies, 13 (93\%) involved interventions. Sixty-three percent of studies included solely Hispanic or Latino participants, and $37 \%$ of studies involved multiethnic samples. Eighty-nine percent of studies were conducted within the United States, and $9 \%$ were conducted in Mexico. Eighty-two percent of studies occurred in urban settings, $11 \%$ involved participants in both urban and rural settings, and $7 \%$ occurred in rural settings. On average, study samples included 203 Hispanic or Latino participants (range 8-1248) who were $73 \%$ female (range $13.8-100 \%$ ), and 29 years old (range 3.7-73.7).

\section{Guidelines for data collection}

The initial set of guidelines reviewed were standards pertaining to data collection. Percentages of articles reporting guidelines for data collection are listed in Table 2. A majority of articles (89\% of accelerometry studies and $93 \%$ of pedometry studies) reported the device manufacturer and model. Our review found that $73 \%$ of accelerometry articles and $40 \%$ of pedometry articles reported device placement (e.g. on the left hip). Slightly more than half (59\%) of the accelerometry articles and $80 \%$ of pedometry articles reported providing the participants with specific instructions concerning wearing the device (e.g. remove during bathing). Sixty-six percent of accelerometry articles and $73 \%$ of pedometry articles reported the number of days of device wear that were required to include participants in analyses. Our review found that only $21 \%$ of accelerometry articles and $47 \%$ of pedometry articles reported measures or indicators of compliance with device use, such as the use of PA logs or reminders via email or phone. Very few (11 \% of accelerometry articles and $40 \%$ of pedometry articles) articles reported providing instructions for device wear in Spanish. Reporting on epoch length was fairly high, with $82 \%$ of accelerometry articles reporting the preset epochs at which PA data were sampled.

\section{Guidelines for data definitions and processing}

Additional guidelines published by Ward et al. [6] recommended standardized data definitions and processing procedure. Table 2 lists percentages of articles that reported following these guidelines. Only $7 \%$ of accelerometry articles reported their definition of an acceptable hour (i.e. the number of minutes in which a predetermined level of 'counts' were registered by the accelerometer for that hour to be included in the data analyses). The investigator's definition of an acceptable day (i.e. the amount of absolute time or a percentage of a measurement period that a device was worn for the data from that day to be included in the data analyses), was reported more frequently, with $75 \%$ of articles reporting this aspect. As there are often compliance issues with participants wearing continuous monitoring devices throughout the sample period, it is important to report the procedure for handling missing data. In this study, only $11 \%$ of articles reported the procedure used for handling periods of missing data. Ward, et al. [6] recommend that researchers report the number of wear interruptions (lengths of time during which no activity was recorded) and utilize imputation to replace missing data. However, this information was reported in only $25 \%$ of accelerometer articles.

\section{Guidelines for data reporting}

The remaining nine guidelines that were examined were standards for data reporting. Data for these standards can be calculated and obtained by continuous monitoring devices and their associated software providing summaries of many variable that are useful for measuring and monitoring PA outcomes [6]. Percentages of articles reporting these standards are listed in Table 2. Only $57 \%$ of accelerometry articles reported the average number of valid days of wear. Only $9 \%$ of accelerometry articles reported the average waking time of participants. The percentage of wear time was reported in only $2 \%$ of accelerometry articles. The percentage of the day spent in PA was reported in $23 \%$ of accelerometry articles while the number of continuous PA sessions by level of effort was reported in $14 \%$ of accelerometry articles. The total duration of sedentary activities per day was reported in $25 \%$ of articles. Finally, the total duration of sleep per day was reported in only one accelerometry article $(5 \%)$. The total duration of PA per day was reported in just $16 \%$ of accelerometry articles, but total pedometer step counts were reported in $86 \%$ of pedometry articles.

\section{Discussion}

This purpose of this systematic review was to compare the reporting of continuous monitoring variables in studies that included Hispanic populations to published 
Table 1 Article characteristics

\begin{tabular}{|c|c|c|c|c|c|c|c|}
\hline Author and year & Study design & Sample ethnicity & Country & Setting & $\begin{array}{l}\text { Hispanic or Latino } \\
\text { participants (n) }\end{array}$ & $\begin{array}{l}\text { Female } \\
(\%)^{\mathrm{a}}\end{array}$ & $\begin{array}{l}\text { Mean age } \\
\text { (years) }^{\mathrm{a}}\end{array}$ \\
\hline \multicolumn{8}{|l|}{ Accelerometer articles } \\
\hline Ainsworth et al., 2013 [24] & Cross-sectional & Hispanic or Latina & USA & Urban & 139 & 100.0 & 28.3 \\
\hline Alhassan et al., 2007 [25] & Cross-sectional & Latino & USA & Urban & 32 & 37.5 & 3.7 \\
\hline Boudreau et al., 2013 [26] & Intervention & Latino & USA & Urban & 41 & 61.5 & - \\
\hline Bacardí-Gascón et al.,2004 [27] & Cross-sectional & Mexican & Mexico & Rural & 100 & 100.0 & 53.0 \\
\hline Bacardí-Gascón et al., 2011 [28] & Cross-sectional & Mexican & Mexico & Urban & 35 & 51.0 & 4.4 \\
\hline Bennett et al., 2006 [29] & Cross-sectional & Multiethnic & USA & Urban & 182 & 64.0 & - \\
\hline Butte et al., 2007 [30] & Cross-sectional & Hispanic & USA & Urban & 897 & 51.0 & 10.8 \\
\hline Byrd-Williams et al., 2007 [31] & Cross-sectional & Multiethnic & USA & Urban & 106 & 50.0 & 9.4 \\
\hline Byrd-Williams et al., 2010 [32] & Intervention & Hispanic & USA & Urban & 38 & 50.0 & - \\
\hline Casazza et al., 2009 [33] & Cross-sectional & Hispanic-American & USA & Urban & 55 & - & - \\
\hline Christensen et al., 2012 [34] & Cross-sectional & Mexican & Mexico & Rural & 64 & 63.0 & 40.7 \\
\hline Clarke et al., 2007 [35] & Intervention & Multiethnic & USA & Urban & 69 & 100.0 & 27.0 \\
\hline Davis et al., 2011 [36] & Intervention & Hispanic or Latina & USA & Urban & 38 & 100.0 & 15.8 \\
\hline Evenson et al., 2012 [37] & Cross-sectional & Multiethnic & USA & Urban and rural & 530 & 50.0 & 70.0 \\
\hline Gay et al., 2013 [38] & Cross-sectional & Multiethnic & USA & Urban & 118 & 68.6 & 48.0 \\
\hline Godard et al., 2012 [39] & Cross-sectional & Hispanic or Latino & Chile & Urban & 109 & 38.5 & - \\
\hline Gortmaker et al., 2012 [40] & Cross-sectional & Multiethnic & USA & Urban and rural & 1248 & - & - \\
\hline Ham et al., 2010 [41] & Cross-sectional & Multiethnic & USA & Urban and rural & 658 & 51.5 & - \\
\hline Hennessy et al., 2010 [42] & Cross-sectional & Multiethnic & USA & Rural & 19 & 65.8 & 9.1 \\
\hline Holman et al., 2011 [43] & Cross-sectional & Multiethnic & USA & Urban and rural & 1038 & 49.2 & 13.0 \\
\hline Hoos et al., 2012 [44] & Cross-sectional & Hispanic or Latina & USA & Urban & 71 & 100.0 & 43.0 \\
\hline Kligerman et al., 2006 [45] & Cross-sectional & Mexican-American & USA & Urban & 60 & 27.0 & 16.2 \\
\hline Koniak-Griffin et al., 2013 [46] & Cross-sectional & Mexican-American & USA & Urban & 223 & 100.0 & 44.6 \\
\hline Layne et al., 2011 [47] & Cross-sectional & Multiethnic & USA & Urban & 71 & 100.0 & 46.6 \\
\hline Lee et al., 2012 [48] & Cross-sectional & Multiethnic & USA & Urban & 148 & 100.0 & 41.4 \\
\hline Lohman et al., 2006 [49] & Cross-sectional & Multiethnic & USA & Urban & 337 & 100.0 & 12.0 \\
\hline Lovasi et al., 2011 [50] & Cross-sectional & Multiethnic & USA & Urban & 355 & - & - \\
\hline Marquez et al., 2008 [51] & Cross-sectional & Hispanic or Latino & USA & Urban & 148 & 83.0 & 29.4 \\
\hline Marquez et al., 2011 [52] & Cross-sectional & Hispanic or Latino & USA & Urban & 174 & 73.6 & 27.4 \\
\hline Marshall et al., 2013 [53] & Intervention & Hispanic or Latina & USA & Urban & 180 & 100.0 & 36.9 \\
\hline McClain et al., 2011 [54] & Cross-sectional & Multiethnic & USA & Urban & 40 & 100.0 & 9.4 \\
\hline Medina et al., 2013 [55] & Cross-sectional & Mexican & Mexico & Urban & 262 & 48.3 & 37.2 \\
\hline Mendoza et al., 2013 [56] & Cross-sectional & Hispanic or Latino & USA & Urban & 96 & 40.0 & 4.7 \\
\hline Hernandez et al., 2013 [57] & Cross-sectional & Mexican & Mexico & Urban & 71 & - & - \\
\hline Nicaise et al., 2011 [58] & Cross-sectional & Hispanic or Latina & USA & Urban & 105 & 100.0 & 35.9 \\
\hline Olvera et al., 2011 [59] & Longitudinal & Hispanic or Latina & USA & Urban & 102 & 100.0 & 36.0 \\
\hline Ramirez-Marrero et al., 2008 [60] & Cross-sectional & Hispanic or Latino & USA (Puerto Rico) & Urban & 58 & 39.6 & 46.5 \\
\hline Ruiz et al., 2011 [61] & Intervention & Hispanic or Latino & USA & Urban & 212 & - & - \\
\hline Sanchez et al., 2007 [62] & Cross-sectional & Multiethnic & USA & Urban & 115 & 13.8 & - \\
\hline Schaefer et al., 2013 [63] & Intervention & Hispanic or Latino & USA & Rural & 170 & - & - \\
\hline Spruijt-Metz et al., 2009 [64] & Cross-sectional & Hispanic or Latina & USA & Urban & 10 & 100.0 & 12.1 \\
\hline Trost et al., 2012 [65] & Cross-sectional & Multiethnic & USA & Urban & 251 & - & - \\
\hline
\end{tabular}


Table 1 Article characteristics (Continued)

\begin{tabular}{|c|c|c|c|c|c|c|c|}
\hline Vella et al., 2011 [66] & Cross-sectional & Hispanic or Latina & USA & Urban & 60 & 100.0 & 25.2 \\
\hline Wilbur et al., 2012 [67] & Cross-sectional & Hispanic or Latino & USA & Urban & 174 & 73.6 & 66.0 \\
\hline \multicolumn{8}{|l|}{ Pedometer articles } \\
\hline Bender et al., 2013 [68] & Intervention & Hispanic & USA & Urban & 33 & 76.0 & 15.3 \\
\hline Coffman et al., 2013 [69] & Intervention & Latina & USA & Urban & 27 & 100.0 & 47.0 \\
\hline D'Alonzo et al., 2004 [70] & Intervention & Multiethnic & USA & Urban & 8 & 100.0 & 26.5 \\
\hline D'Alonzo et al., 2007 [71] & Cross-sectional & Hispanic or Latina & USA and Costa Rica & Urban & 17 & 100.0 & 14.7 \\
\hline Dauenhauer et al., 2011 [72] & Cross-sectional & Multiethnic & USA & Urban & 54 & 53.5 & 9.8 \\
\hline Drieling et al., 2013 [73] & Cross-sectional & Hispanic or Latino & USA & Urban & 207 & 76.8 & 31.1 \\
\hline Hernandez et al., 2013 [74] & Intervention & Hispanic or Latino & USA & Urban & 572 & 77.1 & 73.7 \\
\hline Johnson et al., 2010 [75] & Cross-sectional & Multiethnic & USA & Urban and rural & 308 & 53.1 & 10.4 \\
\hline Keller et al., 2011 [76] & Cross-sectional & Hispanic or Latina & USA & Urban & 271 & 100.0 & 55.5 \\
\hline Kulinna et al., 2012 [77] & Intervention & Multiethnic & USA & Urban and rural & 271 & 48.1 & 9.7 \\
\hline Oh et al., 2012 [78] & Cross-sectional & Hispanic or Latino & USA & Urban & 101 & 58.0 & 14.8 \\
\hline Pekmezi et al., 2013 [79] & Intervention & Hispanic or Latina & USA & Urban & 43 & 100.0 & 41.6 \\
\hline Shelton et al., 2009 [80] & Cross-sectional & Multiethnic & USA & Urban & 680 & - & - \\
\hline
\end{tabular}

guidelines on data acquisition, processing and reporting. These guidelines were published in an effort to promote the standardization of future data acquisition, processing, and data reporting across studies using continuous monitoring devices. Findings from this review confirm that many of the issues identified by Ward et al. [6] in data collection, processing, and reporting still persist today, and are particularly prevalent in studies using continuous monitoring devices in Hispanic populations. Slightly over half of the articles reviewed met standards for data collection, with only a third of articles meeting standards for data processing. The majority of pedometer articles met standards for data reporting; however, less than $20 \%$ of accelerometer articles met these same standards [11-15].

The first set of guidelines reviewed were standards pertaining to data collection. The majority of studies reported the make and model of the device used. Reporting the make and model of the device is important for considerations of practicality, cost, monitor compatibility, and the reliability and validity of reported data [6]. Reporting on device placement was also high among accelerometer and pedometer articles. Since the location for device placement on subjects may vary by subject demographics (e.g. age) and affects data outputs, this information is important for helping readers interpret the published data [6]. The majority of articles reported providing instructions on device wear to participants; however, very few accelerometer articles and less than half of pedometer articles reported providing these instructions in Spanish. Efficient and reliable data collection requires that investigators provide and participants comply with clear instructions for device wear, and failure to do so can result in misleading and inaccurate data [6]. Failure to provide instructions in the participant's preferred language may lead to miscommunication that could negatively impact data collection processes.

The majority of articles in this review reported on device wear, indicating the number of days of wear required for participants to be included in analyses so that PA patterns could be more accurately estimated. The number of days of device wear is also an important component of monitoring protocols and may vary based on study setting, subject demographics, research questions, and study resources. According to Ward et al., 7 day monitoring protocols with at least 3-5 days of monitoring is needed in order to estimate habitual PA among adults and children [6]. Few accelerometer articles and half of pedometer articles reported the use of compliance efforts such as activity logs and phone call reminders to participants. Use of these compliance efforts for device use can also help researchers obtain accurate estimates of habitual PA, adding to the interpretability of PA findings by providing specific information on activities and location of activity [6]. For preset sampling periods, or epochs, Ward et al. recommend 1-min sampling epochs for adults and 15-s sampling epochs for children. Almost all accelerometer articles met the guideline for reporting preset epochs. This guideline is important for accurate measurement of PA since different epoch lengths can result in different estimates of moderate and vigorous PA.

The second set of guidelines published by Ward et al. [6] outlined data definitions and processing standards. The first standard addressed criteria for the constitution of time periods for device wear. Defining the amount of device wear that constitutes an acceptable hour of wear for inclusion in analyses is important, as short durations 
of device wear may provide less accurate estimates of habitual PA. For accurate interpretation of data, the definition of an acceptable hour should be standardized and applied uniformly to all study participants; however, only $7 \%$ of accelerometer articles reported the definition of an acceptable hour used by the investigators. The handling of missing data is another important guideline for data processing. Only $11 \%$ of articles reported a procedure for handling missing data. Missing data for sampling periods can significantly skew the data, causing PA measurements to be severely over- or underestimated [6]. Reporting on the number and length of continuous sessions in which PA occurs was also poor. The number and length of continuous sessions lends to the interpretation of data and definition PA patterns and can also have important health implications for the study population [6].

The remaining nine guidelines examined were standards for data reporting. Effective comparisons between studies require the standardized reporting of PA variables. However, few of these standards were reported in the articles included in this review. Only $10 \%$ of articles reported information on participant use such as average waking time and percentage of wear time. Other PA variables such as duration of PA per day, percentage of the day spent in PA, the number of continuous PA sessions by level of effort, the total duration of sedentary activities and duration of sleep time per day were also underreported. The only standard consistently reported in the majority of pedometer articles was the total pedometer step counts.

Findings from this study have important implications for research and practice. Based on the results of our analyses, few investigators report the information necessary to be compliant with all of the recommended guidelines for data collection, processing and reporting of PA obtained from continuous monitoring technologies. Researchers should include instructions in the native or preferred language of the population they are targeting. Non-English speaking and/or immigrant minorities may be apprehensive of continuous monitoring devices. Providing instructions in their native language will serve to build trust between participants and the research team, promotes compliance, and ensures that devices are worn appropriately and that their use and placement is understood by participants. Furthermore, standards on data definitions and processing were poorly reported. Many investigators rely on previously conducted studies in order to compile evidence and make comparisons of

Table 2 Percentages of articles reporting guidelines for continuous monitoring data

\begin{tabular}{|c|c|c|}
\hline Guideline & Accelerometer articles $(n=44)(\%)$ & Pedometer articles $(n=13)(\%)$ \\
\hline \multicolumn{3}{|l|}{ Data collection standards } \\
\hline Device manufacturer and model & 88.6 & 92.9 \\
\hline Placement of device on subjects & 72.7 & 40.0 \\
\hline Provision of instructions for device wear to subjects & 59.1 & 80.0 \\
\hline Number of days required for inclusion in analyses & 65.9 & 73.3 \\
\hline Use of compliance efforts for device use & 20.5 & 46.7 \\
\hline Provision of instructions for device wear in Spanish & 11.4 & 40.0 \\
\hline Epoch length & 81.8 & - \\
\hline \multicolumn{3}{|l|}{ Data inclusion standards } \\
\hline Definition of an acceptable hour for inclusion in analyses & 6.8 & - \\
\hline Definition of an acceptable day for inclusion in analyses & 75.0 & - \\
\hline Procedure for handling periods for which data was missing & 11.4 & - \\
\hline Length of continuous PA sessions & 25.0 & - \\
\hline \multicolumn{3}{|l|}{ Data reporting standards } \\
\hline Average number of valid days & 56.8 & - \\
\hline Average waking time & 9.1 & - \\
\hline Percentage of wear time & 2.3 & - \\
\hline Percentage of day spent in PA & 22.7 & - \\
\hline Number of continuous PA sessions by level of effort & 13.6 & - \\
\hline Total duration of sedentary activities per day & 25.0 & - \\
\hline Total duration of sleep per day & 4.6 & - \\
\hline Total duration of PA per day & 15.9 & - \\
\hline Total step count & - & 85.7 \\
\hline
\end{tabular}


outcomes across studies and populations. However, this review has revealed that it is very often unclear how previous researchers collected and processed their data, potentially resulting in misinterpretations and inaccurate use of PA. This can further perpetuate beliefs about PA patterns that are unfounded and can misinform policy recommendations. Likewise, researchers must increase their reporting of the data standards they employed in their investigations. This information is also critical in allowing researchers to compare PA outcomes across studies in order to increase our understanding of PA behaviors in specific populations. Researchers who use continuous monitoring devices must make a stronger effort to follow and report the guidelines provided by Ward et al. [6] and outlined in this study.

Journals and the scientific community would benefit greatly from requiring authors of papers involving continuously monitored PA to submit standardized tables or appendices listing (1) all data collection strategies they utilized, (2) all standards by which decisions to include or exclude data from analyses were made, and (3) standard variables that can be computed from their datasets. We recommend that these standards be followed and reported to make the data and use of these devices meaningful and generalizable. Improving the reporting of standards can provide important information that can help fight ethnic disparities in PA among Hispanic populations.

\section{Conclusion}

Lack of consensus and inconsistent reporting limits our ability to make comparisons across studies and limits our understanding of the dose-response relationship between PA and health outcomes, particularly in special populations such as Hispanics [16]. Failure to achieve uniformity in reporting can leave future research, policy, and national guidelines, such as recommendations for PA and strategies to improve compliance in PA interventions, misinformed $[1,12]$. Findings from this study showed that, in studies using continuous monitoring devices in Hispanic populations, reporting on data collection methods is inconsistent and reporting on methods and definitions for data processing is poor. Failure to follow standard guidelines for data collection, processing, and reporting has a number of consequences. First, these failures prohibit effective generalization of the level of physical activity for Hispanics from a particular sample and study to the population. Second, these failures may produce inaccuracies in monitoring and tracking of PA patterns and related health outcomes, which may prevent us from effectively intervening in this population. Finally, these omissions limit our ability to make comparisons across studies between Hispanics and other ethnic populations or comparisons within varying groups of Hispanics, which can provide additional insights on PA trends and disparities [81].
Abbreviation

PA: Physical activity.

Competing interests

The authors declare that they have no competing interests.

\section{Authors' contributions}

CSL, REL, and DPO conceived of the study and participated in its design and coordination. CSL, NHP, EGS, and JRC participated in literature review and article coding. NHP and EGS pooled and analyzed data from coded articles. CSL, NHP, EGS, JRC, MRG, and REL helped to draft the manuscript. All authors read and approved the final manuscript.

\section{Authors' information}

Not applicable

\section{Availability of data and materials}

Not applicable

\section{Acknowledgements}

We thank Juan Lopez y Taylor, Edtna Jauregui, Cynthia Castro, Lucie Levesque, Lorna McNeill and Teresia O'Connor, who were involved in this Multinational Collaboration project and who provided support and feedback. We would also like to acknowledge the numerous research assistants and students who aided with coding: Heather Adamus-Leach, Anjali Agrawal, Kate Bosselman, Molly Bryant, Towfik Elmi, Alex Milow, Maria Mohseni, Abrianna Nichols, Ann Pacheco, Aiza Prades, Steven Rhee, Fiorella Saavedra, and Amanda Summers.

This work was completed as part of a funded project called Multinational Collaboration to Increase Physical Activity in Hispanics (1R13CA162816), awarded to Dr. Rebecca E. Lee by the Applying Collaboration in Translational Investigation for Valuable Activity Recommendations (ACTIVAR) group.

\section{Funding}

This work was completed as part of a funded project called Multinational Collaboration to Increase PhysicalActivity in Hispanics (1R13CA162816), awarded to Dr. Rebecca E. Lee by the Applying Collaboration inTranslational Investigation for Valuable Activity Recommendations (ACTIVAR) group.

\section{Author details}

${ }^{1}$ Texas Obesity Research Center, Department of Health and Human Performance, University of Houston, Garrison Gymnasium Room 104, 3855 Holman Street, Houston, TX 77204-6015, USA. ${ }^{2}$ School of Human Evolution and Social Change, Arizona State University, 900 S. Cady Mall, Tempe, AZ 85287, USA. ${ }^{3}$ School of Nursing, University of Texas Health Science Center, 6901 Bertner, Houston, TX 77030, USA. ${ }^{4}$ Center for Health Promotion and Disease Prevention, College of Nursing and Health Innovation, Arizona State University, 500 N. 3rd Street, Phoenix, AZ 85004, USA.

Received: 28 April 2015 Accepted: 14 September 2015

Published online: 18 September 2015

\section{References}

1. Chen KY, Bassett Jr DR. The technology of accelerometry-based activity monitors: current and future. Med Sci Sports Exerc. 2005;37(11 Suppl):S490-500.

2. Corder K, Brage S, Ekelund U. Accelerometers and pedometers: methodology and clinical application. Curr Opin Clin Nutr Metab Care. 2007;10(5):597-603.

3. Ramirez-Marrero FA, Rivera-Brown AM, Nazario CM, Rodriguez-Orengo JF, Smit E, Smith BA. Self-reported physical activity in Hispanic adults living with HIV: comparison with accelerometer and pedometer. J Assoc Nurses AIDS Care. 2008;19(4):283-94.

4. Schutz $Y$, Weinsier $S$, Terrier $P$, Durrer D. A new accelerometric method to assess the daily walking practice. Int J Obes Relat Metab Disord. 2002;26(1):111-8.

5. Tudor-Locke C, Ainsworth BE, Thompson RW, Matthews CE. Comparison of pedometer and accelerometer measures of free-living physical activity. Med Sci Sports Exerc. 2002;34(12):2045-51.

6. Ward DS, Evenson KR, Vaughn A, Rodgers AB, Troiano RP. Accelerometer use in physical activity: best practices and research recommendations. Med Sci Sports Exerc. 2005;37(11 Suppl):S582-8 
7. Westerterp KR. Assessment of physical activity: a critical appraisal. Eur J Appl Physiol. 2009;105(6):823-8.

8. John D, Freedson P. ActiGraph and Actical physical activity monitors: a peek under the hood. Med Sci Sports Exerc. 2012;44(1 Suppl 1):S86-9.

9. Trost SG, Mclver KL, Pate RR. Conducting accelerometer-based activity assessments in field-based research. Med Sci Sports Exerc. 2005;37(11 Suppl):S531-43.

10. Bassett Jr DR, Ainsworth BE, Leggett SR, Mathien CA, Main JA, Hunter DC, et al. Accuracy of five electronic pedometers for measuring distance walked. Med Sci Sports Exerc. 1996;28(8):1071-7.

11. Chen KY, Janz KF, Zhu W, Brychta RJ. Redefining the roles of sensors in objective physical activity monitoring. Med Sci Sports Exerc. 2012;44(1 Suppl 1):S13-23.

12. Freedson P, Bowles HR, Troiano R, Haskell W. Assessment of physical activity using wearable monitors: recommendations for monitor calibration and use in the field. Med Sci Sports Exerc. 2013;44(1 Suppl 1):S1-4.

13. Herrmann SD, Barreira TV, Kang M, Ainsworth BE. How many hours are enough? Accelerometer wear time may provide bias in daily activity estimates. J Phys Act Health. 2013;10(5):742-9.

14. Lee PH. Data imputation for accelerometer-measured physical activity: the combined approach. Am J Clin Nutr. 2013;97(5):965-71.

15. Vaha-Ypya H, Vasankari T, Husu P, Suni J, Sievanen H. A universal, accurate intensity-based classification of different physical activities using raw data of accelerometer. Clin Physiol Funct Imaging. 2014;35:64-70.

16. Oliver M, Schofield GM, Badland HM, Shepherd J. Utility of accelerometer thresholds for classifying sitting in office workers. Prev Med. 2010;51(5):357-60.

17. Centers for Disease Control and Prevention. Facts about physical activity center for disease control. 2008. http://www.cdc.gov/physicalactivity/data/ facts.html. August 1, 2014.

18. Hallal PC, Andersen LB, Bull FC, Guthold R, Haskell W, Ekelund U. Global physical activity levels: surveillance progress, pitfalls, and prospects. Lancet. 2012;380(9838):247-57.

19. Mathers C, Fat DM, Boerma JT. The global burden of disease: 2004 update. Geneva: World Health Organization; 2008.

20. Finck Barboza C, Monteiro SM, Barradas SC, Sarmiento OL, Rios P, Ramirez A, et al. Physical activity, nutrition and behavior change in Latin America: a systematic review. Glob Health Promot. 2013;20(4 Suppl):65-81.

21. Galaviz KI, Harden SM, Smith E, Blackman KC, Berrey LM, Mama SK, et al. Physical activity promotion in Latin American populations: a systematic review on issues of internal and external validity. Int J Behav Nutr Phys Act. 2014;11:77.

22. Moher D, Liberati A, Tetzlaff J, Altman DG. Preferred reporting items for systematic reviews and meta-analyses: the PRISMA statement. Int J Surg. 2009:8(5):336-41.

23. World Bank. Country and Lending Groups. 2014. http://data.worldbank.org/ about/country-and-lending-groups. Accessed August 1, 2014.

24. Ainsworth BE, Keller C, Herrmann S, Belyea M, Records K, Nagle-Williams A, et al. Physical activity and sedentary behaviors in postpartum Latinas: Madres para la Salud. Med Sci Sports Exerc. 2013;45(7):1298-306

25. Alhassan $S$, Sirard JR, Robinson TN. The effects of increasing outdoor play time on physical activity in Latino preschool children. Int J Pediatr Obes. 2007;2(3):153-8.

26. Boudreau ADA, Kurowski DS, Gonzalez WI, Dimond MA, Oreskovic NM Latino families, primary care, and childhood obesity: a randomized controlled trial. Am J Prev Med. 2013:44(3):S247-S57.

27. Bacardí-Gascón M, Rosales-Garay P, Jiménez-Cruz A. Effect of diabetes intervention programs on physical activity among migrant Mexican women with type 2 diabetes. Diabetes Care. 2004;27(2):616.

28. Bacardí-Gascón M, Reveles-Rojas C, López Gail W, Crawford P, Jiménez-Cruz A. Validity of a physical activity questionnaire used with parents of preschool children in Mexico. Nutr Hosp. 2011;26(1):244-5.

29. Bennett GG, Wolin KY, Viswanath K, Askew S, Puleo E, Emmons KM. Television viewing and pedometer-determined physical activity among multiethnic residents of low-income housing. Am J Public Health. 2006;96(9):1681-5.

30. Butte NF, Puyau MR, Adolph AL, Vohra FA, Zakeri I. Physical activity in nonoverweight and overweight Hispanic children and adolescents. Med Sci Sport Exerc. 2007:39(8):1257-66.

31. Byrd-Williams C, Kelly LA, Davis JN, Spruijt-Metz D, Goran MI. Influence of gender, BMl and Hispanic ethnicity on physical activity in children. Int J Pediatr Obes. 2007;2(3):159-66.
32. Byrd-Williams CE, Belcher BR, Spruijt-Metz D, Davis JN, Ventura EE, Kelly L, et al. Increased physical activity and reduced adiposity in overweight Hispanic adolescents. Med Sci Sport Exerc. 2010;42(3):478.

33. Casazza K, Dulin-Keita A, Gower BA, Fernandez JR. Differential influence of diet and physical activity on components of metabolic syndrome in a multiethnic sample of children. J Am Diet Assoc. 2009;109(2):236-44.

34. Christensen DL, Alcalá-Sánchez I, Leal-Berumen I, Conchas-Ramirez M, Brage S. Physical activity, cardio-respiratory fitness, and metabolic traits in rural mexican tarahumara. Am J Hum Biol. 2012;24(4):558-61.

35. Clarke KK, Freeland-Graves J, Klohe-Lehman DM, Milani TJ, Nuss HJ, Laffrey S. Promotion of physical activity in low-income mothers using pedometers. J Am Diet Assoc. 2007;107(6):962-7.

36. Davis JN, Gyllenhammer LE, Vanni AA, Meija M, Tung A, Schroeder ET, et al. Startup circuit training program reduces metabolic risk in Latino adolescents. Med Sci Sport Exerc. 2011;43(11):2195.

37. Evenson KR, Buchner DM, Morland KB. Objective measurement of physical activity and sedentary behavior among US adults aged 60 years or older. Prev Chronic Dis. 2012;9.

38. Gay JL, Kohl H. Salinas JJ. Fisher-Hoch SP. Contribution of Occupation to High Doses of Light-Intensity Activity and Cardiovascular Risk Factors among Mexican American Adults. J Phys Act Health: McCormick JB; 2013.

39. Godard C, Román M. Rodríguez MdP, Leyton B, Salazar G. Variabilidad de la actividad física en niños chilenos de 4 a 10 años: estudio por acelerometría. Arch Argent Pediatr. 2012;110(5):388-93.

40. Gortmaker SL, Lee R, Cradock AL, Sobol AM, Duncan DT, Wang YC Disparities in youth physical activity in the United States: 2003-2006. Med Sci Sports Exerc. 2012;44(5):888-93.

41. Ham SA. Disparities in data on Healthy People 2010 physical activity objectives collected by accelerometry and self-report. Am J Public Health. 2010;100(S1):S263.

42. Hennessy E, Hughes SO, Goldberg JP, Hyatt RR, Economos CD. Parent-child interactions and objectively measured child physical activity: a cross-sectional study. Int J Behav Nutr Phys Act. 2010;7(1):71.

43. Holman RM, Carson V, Janssen I. Does the fractionalization of daily physical activity (sporadic vs. bouts) impact cardiometabolic risk factors in children and youth. PloS one. 2011;6(10), e25733.

44. Hoos T, Espinoza N, Marshall S, Arredondo EM. Validity of the global physical activity questionnaire (GPAQ) in adult Latinas. J Phys Act Health. 2012;9(5):698.

45. Kligerman M, Sallis JF, Ryan S, Frank LD, Nader PR. Association of neighborhood design and recreation environment variables with physical activity and body mass index in adolescents. Am J Health Promot. 2007;21(4):274-7.

46. Koniak-Griffin D, Brecht M-L, Takayanagi S, Villegas J, Melendrez M. Physical Activity and Cardiometabolic Characteristics in Overweight Latina Women. J Immigr Minor Health. 2014;16(5):856-64

47. Layne CS, Mama SK, Banda JA, Lee RE. Development of an ecologically valid approach to assess moderate physical activity using accelerometry in community dwelling women of color: A cross-sectional study. Int J Behav Nutr Phys Act. 2011;8(1):21.

48. Lee RE, Mama SK, Medina AV, Ho A, Adamus HJ. Neighborhood factors influence physical activity among African American and Hispanic or Latina women. Health Place. 2012;18(1):63-70.

49. Lohman TG, Ring K, SCHMITZ KH, TREUTH MS, LOFTIN M, YANG S, et al. Associations of body size and composition with physical activity in adolescent girls. Med Sci Sport Exerc. 2006;38(6):1175.

50. Lovasi GS, Jacobson JS, Quinn JW, Neckerman KM, Ashby-Thompson MN, Rundle A. Is the environment near home and school associated with physical activity and adiposity of urban preschool children? J Urban Health 2011;88(6):1143-57.

51. Marquez DX, Bustamante EE, McAuley E, Roberts DE. Active or sedentary? Objectively measured physical activity of Latinos and implications for intervention. J Phys Act Health. 2008;5(4):559-70.

52. Marquez DX, Hoyem R, Fogg L, Bustamante EE, Staffileno B, Wilbur J. Physical activity of urban community-dwelling older Latino adults. J Phys Act Health. 2011:8(2):S161.

53. Marshall SJ, Nicaise V, Ji M, Huerta C, Haubenstricker J, Levy SS, et al. Using step cadence goals to increase moderate-to-vigorous-intensity physical activity. Med Sci Sport Exerc. 2013;45(3):592-602.

54. McClain AD, Hsu Y-W, Belcher BR, Nguyen-Rodriguez S, Weigensberg M, Spruijt-Metz D. Physical inactivity, but not sedentary behavior or energy 
intake, is associated with higher fat mass in Latina and African American girls. Ethn Dis. 2011;21(4):458.

55. Medina C, Barquera S, Janssen I. Validity and reliability of the International Physical Activity Questionnaire among adults in Mexico. Rev Panam Salud Pública. 2013;34(1):21-8.

56. Mendoza JA, McLeod J, Chen T-A, Nicklas TA, Baranowski T. Convergent Validity of Preschool Children's Television Viewing Measures among LowIncome Latino Families: A Cross-Sectional Study. Child Obes. 2013;9(1):29-34.

57. Hernández M, de Jesús MT, Dorantes Pineda CM, Ramos Ibáñez N, OrtizHernández L. Actividad física en un grupo de escolares de la Ciudad de México: factores asociados y puntos de corte utilizando acelerometría. Bol Med Hosp Infant Mex. 2013;70(5):372-9.

58. Nicaise V, Marshall S, Ainsworth BE. Domain-specific physical activity and self-report bias among lowincome Latinas living in San Diego County. J Phys Act Health. 2011;8(7):881.

59. Olvera N, Smith DW, Lee C, Liu J, Lee J, Kim J-H, et al. Comparing high and low acculturated mothers and physical activity in Hispanic children. J Phys Act Health. 2011;8(2):S206.

60. Ramírez-Marrero FA, Rivera-Brown AM, Nazario CM, Rodríguez-Orengo JF, Smit E, Smith BA. Selfreported physical activity in Hispanic adults living with HIV: comparison with accelerometer and pedometer. J Assoc Nurses AIDS Care. 2008;19(4):283-94.

61. Ruiz R, Gesell SB, Buchowski MS, Lambert W, Barkin SL. The relationship between Hispanic parents and their preschool-aged children's physical activity. Pediatrics. 2011;127(5):888-95.

62. Sanchez A, Norman GJ, Sallis JF, Calfas KJ, Cella J, Patrick K. Patterns and correlates of physical activity and nutrition behaviors in adolescents. Am J Prev Med. 2007;32(2):124-30.

63. Schaefer SE, Whent $L$, de la Torre A. Use of Worn Accelerometers to Measure Physical Activity in Mexican-heritage Children in California's Central Valley. J Nutr Educ Behav. 2013;4(45):S89.

64. Spruijt-Metz D, Belcher B, Anderson D, Lane CJ, Chou C-P, Salter-Venzon D, et al. A high-sugar/lowfiber meal compared with a low-sugar/high-fiber meal leads to higher leptin and physical activity levels in overweight Latina females. Am J Diet Assoc. 2009;109(6):1058-63.

65. Trost SG, McCoy TA, Vander Veur SS, Mallya G, Duffy ML, Foster GD. Physical activity patterns of innercity elementary schoolchildren. Med Sci Sport Exerc. 2013:45(3):470-4.

66. Vella CA, Ontiveros D, Zubia RY, Dalleck L. Physical activity recommendations and cardiovascular disease risk factors in young Hispanic women. J Sports Sci. 2011;29(1):37-45.

67. Wilbur J, Marquez DX, Fogg L, Wilson RS, Staffileno BA, Hoyem RL, et al. The relationship between physical activity and cognition in older Latinos. J Gerontol B Psychol Sci Soc Sci. 2012;67(5):525-34.

68. Bender MS, Nader PR, Kennedy C, Gahagan S. A culturally appropriate intervention to improve health behaviors in Hispanic mother-child dyads. Child Obes. 2013;9(2):157-63.

69. Coffman MJ, Ferguson BL, Steinman L, Talbot LA, Dunbar-Jacob J. A health education pilot for Latina women with diabetes. Clin Nurs Res. 2012;1054773812451746

70. D'Alonzo KT, Stevenson JS, Davis SE. Outcomes of a program to enhance exercise self-efficacy and improve fitness in Black and Hispanic college-age women. Res Nurs Health. 2004;27(5):357-69.

71. D'Alonzo KT, Cortese LB. An investigation of habitual and incidental physical activity among Costa Rican and Costa Rican American teenage girls. Journal of Transcultural Nursing. 2007;18(3):201-7.

72. Dauenhauer BD, Keating XD. The influence of physical education on physical activity levels of urban elementary students. Res Q Exerc Sport. 2011;82(3):512-20.

73. Drieling RL, Rosas LG, Ma J, Stafford RS. Community resource utilization, psychosocial health, and sociodemographic factors associated with diet and physical activity among low-income obese Latino immigrants. J Acad Nutr Diet. 2014;114(2):257-65.

74. Hernandez R, Prohaska TR, Wang P-C, Sarkisian CA. The Longitudinal Relationship Between Depression and Walking Behavior in Older Latinos The " $i$ Caminemos!" Study. J Aging Health. 2013;25(2):319-41. doi:10.1186/ s12889-015-2266-4.

75. Johnson TG, Brusseau TA, Vincent Graser S, Darst PW, Kulinna PH. Step counts of 10-to 11-year-old children by ethnicity and metropolitan status. J Phys Act Health. 2010;7(3):355-63.
76. Keller C, Fleury J, Perez A, Belyea M, Castro FG. Mujeres en acción: Design and baseline data. J Community Health. 2011;36(5):703-14.

77. Kulinna PH, Brusseau TA, Cothran D, Tudor-Locke C. Changing school physical activity: An examination of individual school designed programs. J Teach Phys Educ. 2012;31(2):113-30.

78. Oh H-J, Hannon J, Williams DP. Physical activity differences by birthplace and sex in youth of Mexican heritage. J Phys Act Health. 2012;9(4):500.

79. Pekmezi D, Dunsiger S, Gaskins R, Barbera B, Marquez B, Neighbors C, et al. Feasibility and acceptability of using pedometers as an intervention tool for Latin. J Phys Act Health. 2013;10(3):451.

80. Shelton RC, Puleo E, Bennett GG, McNeill LH, Goldman RE, Emmons KM. Racial Discrimination and Physical Activity Among Low-Income-Housing Residents. Am J Prev Med. 2009;37(6):541-5.

81. Matthews CE, Hagstromer M, Pober DM, Bowles HR. Best practices for using physical activity monitors in population-based research. Med Sci Sports Exerc. 2012;44(1 Suppl 1):S68-76.

\section{Submit your next manuscript to BioMed Central and take full advantage of:}

- Convenient online submission

- Thorough peer review

- No space constraints or color figure charges

- Immediate publication on acceptance

- Inclusion in PubMed, CAS, Scopus and Google Scholar

- Research which is freely available for redistribution 